\title{
TỈ LỆ BỊ RốI LOẠN LO ÂU VÀ TRẦM CẢM Ở BỆNH NHÂN ĐAU THẮT LƯNG MẠN TÍNH DO THOÁI HÓA CộT SỐNG
}

Vũ Hồng Vân*

\section{TÓM TẮT}

Mục tiêu: Nghiên cứu tỉ lệ có triệu chứng rối loạn lo âu và trầm cảm ở những trường hợp đau lưng mạn tính do thoái hóa cột sống. Đối tượng và phương pháp nghiên cứu: Nghiên cứu mô tả cắt ngang được tiến hành trên 40 bệnh nhân bị đau lưng mạn tính do thoái hóa cột sống. Tỉ lệ bệnh nhân có triệu chứng lo âu và trầm cảm trong các bệnh nhân này được đánh giá theo thang điểm đánh giá lo âu và trầm cảm trong bệnh viện (HADS). Kết quả: Nghiên cứu bao gôm 40 bểnh nhân từ 45 đến 75 tuổi, độ tuổi trung binh là 61,7 tuổi với đô lệch chuẩn là 8,6 . Bênh nhân nam là $15(37,5 \%)$, nữ là $25(62,5 \%)$. Thời gian bi đau lưng trung bình là 2,4 năm giao động từ 1 đến 4 năm. Đánh giá tình trạng lo âu và trầm cảm theo thang điểm HADS có $65 \%$ bênh nhân có triệu chứng lo âu và $55 \%$ có triệu chứng trầm cảm. Trong đó có $27,5 \%$ bênh nhân có dâu hiêu lo âu và $30 \%$ thực sự lo âu; $37,5 \%$ có dấu hiệu trầm cảm và $25 \%$ thực sự trâm cảm. Kết luận: ở bệnh nhân đau lưng mạn tính do thoái hóa, các yếu tố tâm lý đóng vai trò quan trong, bởi vì các bệnh nhân này có nguy cơ bị rối loạn tâm lý lo âu và trầm cảm.

Tư khóa: Thoái hóa cột sống, lo âu, trầm cảm, đau lưng mạn tính.

\section{SUMMARY \\ PREVALENCE OF ANXISTY AND DEPRESSION AMONG PATIENTS WITH CHRONIC LOW BACK PAIN CAUSED BY LUMBAR DEGENERATION}

Objective: To study the prevalence of symptoms of depression and anxiety in individuals with chronic low back pain caused by lumbar degeneration. Metarials and method: Cross sectional study was conducted with sample size of 40 patients with chronic low back pain caused by lumbar degeneration. The prevalence of anxiety and depression among patients was studied by using Hospital Anxiety and Depression Scale (HADS). Results: The study included 40 patients with the mean age of patients was 61.7 years with standard deviation of 8.6. Out of 40 there were $15(37.5 \%)$ men and $25(62.5 \%)$ women in the study sample. The mean duration of symptoms was 2.4 years with a minimum of 1 year and maximum of 4 years. The study found abnormal levels of anxiety and depression among patients with $65 \%$ and $55 \%$ for anxiety and depression respectively. $27.5 \%$ and $30 \%$ were Borderline abnormal for anxiety and depression

*Bênh viên Trung ương Quân đội 108.

Chịu trách nhiệm chính: Vũ Hồng Yến

Email: lethuhai3009@gmail.com

Ngày nhận bài: 19/5/2021

Ngày phản biên khoa học: 21/6/2021

Ngày duyệt bài: 18/7/2021 and $37.5 \%$ and $25 \%$ were abnormal for anxiety and depression as per HADS scale. Conclusion: In patients with with chronic low back pain caused by lumbar degeneration, the psychological factors are important, as patients with with chronic low back pain caused by lumbar degeneration are at risk of experiencing anxiety and depression.

Keywords: Lumbar Degeneration, Depression, Anxiety, Low Back pain

\section{I. ĐĂT VẤN ĐỀ}

Đau cột sống thắt lưng là tình trạng phổ biến với $80 \%$ dân số có biểu hiện đau lưng trong cuộc đời của mỗi người. Một tỉ lề nhỏ (10-40\%) sẽ trở thành bênh lý man tính và trở thành gánh năng cho gia đinh và xã hội [1]. Đau cột sống thắt lưng không phải là một bệnh lý cụ thể; nói đúng hơn đó là dấu hiệu lâm sàng có thể do nhiều bênh lý gây ra. Một trong những nguyên nhân gấy đau cột sống thắt lưng phổ biến nhất là thoai hóa cột sống thắt lưng. Đây là tình trạng bênh có thoái hóa ở đĩa đệm, thân đốt sống và hoặc các khớp liên đốt sống. Đau cột sống thắt lưng mạn tính được xem là một hiện tượng tâm sinh lý, xã hội mà trong đó các yểu tố này tác động lẫn nhau. Các yếu tố tâm lý như sự đau khổ, tâm trang chán nản và phản ứng tự về của cơ thể được báo cáo là có liên quan đến tình trạng đau thắt lưng. Sự xuất hiện của các vấn đề tâm lý này cũng là dấu hiệu nhận biết tình trạng đau lưng từ cấp tính chuyển sang mạn tính. Lo âu, trầm cảm là hai trạng thai tâm lý thường thấy ở bệnh nhân. Các triệu chứng ở cột sống thắt lưng thường đi kèm với các vấn đề tâm lý như buồn phiền, lo âu hoặc trầm cảm [2]. Theo sự tìm hiểu của chúng tôi, tại Việt Nam, mặc dù hiện nay có các nghiên cứu đã được công bố về thoai hóa cột sống thắt lưng. Tuy nhiên, chưa có nghiên cứu nào tìm hiểu về các rối loạn tâm lý ở bệnh nhân đau thắt lưng mạn tinh do thoai hóa cột sống. Chính vì vậy, chúng tôi tiến hành đề tài này với muc tiêu tìm hiểu tî lê có rối loan lo âu và trầm cảm ở những bênh nhân đau thắt lưng mạn tinh do thoai hóa cột sống.

\section{II. ĐỐl TƯỢNG VÀ PHƯƠNG PHÁP NGHIÊN CỨU}

2.1. Đối tương: Các trường hợp đau côt sống thắt lưng mạn tính do thoái hóa đến khám và điều trị tại Khoa khám bệnh đa khoa - Bệnh viện Trung ương Quân đội 108. Tiểu chuẩn lựa chọn: Các bênh nhân có độ tuổi từ 45 đến 75 
tuổi; có thời gian đau lưng kéo dài từ 1 năm trở lên; được chẩn đoán nguyên nhân đau lưng là do thoái hóa cột sống trên hình ảnh. Tiểu chuẩn loại trừ: Các trường hợp đau lưng mạn tinh do các nguyên nhân khác như: Ung thư, xẹp đốt sống loãng xương, chấn thương cột sống....; Bệnh nhân có tiền sử có bệnh lý về tâm thần hoặc có bệnh lý cột sống bẩm sinh.

2.2. Thời gian và địa điểm nghiên cứu: Từ tháng $1 / 2021$ đến tháng $3 / 2021$ tại Khoa khám bệnh - Bệnh viện Trung ương Quân đội 108.

2.3. Thiết kế nghiên cứu và cỡ mẫu: Nghiên cứu mô tả cắt ngang với cỡ mẫu thuận tiện, chọn tất cả các trường hợp đau thắt lưng mạn tinh do thoái hóa cột sống trong 3 tháng.

2.4. Nội dung nghiên cứu: Sử dụng thang điểm đánh giá lo âu và trầm cảm trong bệnh viện (HADS - Hospital Anxiety and Depresion Scale)[3] để đánh giá tình trạng tâm lý ở 40 người bệnh đau thắt lưng mạn tinh nguyên nhân do thoái hóa cột sống đáp ứng đúng tiêu chuẩn lựa chọn và loại trừ. Sau khi điểm HADS của mỗi bệnh nhân được đánh giá sẽ được phân loại như sau: 0-7 điểm: binh thường; 8-10 điểm: có dấu hiệu lo âu hoặc trầm cảm; 11 - 21 điểm: Thực sự có bệnh lo âu hoặc trầm cảm.

\section{KẾT QUẢ NGHIÊN CỨU}

Nghiên cứu tập hợp được 40 bệnh nhân đau cột sống thắt lưng mạn tính do thoái hóa cột sống đáp ứng đủ tiêu chuẩn và loại trừ. Độ tuổi trung binh của 40 bệnh nhân là 61,7 tuổi với độ lệch chuẩn là 8,6 . Trong 40 trường hợp có 15 bệnh nhân nam chiếm $37,5 \%$ và 25 bệnh nhân nữ chiếm $62,5 \%$. Thời gian bị đau lưng trung bình là 2,4 năm (dao động từ 1 đến 4 năm).

Bảng 1. Điểm HADS về tình trạng lo âu và trầm cảm ở 40 bệnh nhân.

\begin{tabular}{|c|c|c|}
\hline Điểm HADS & $\begin{array}{c}\text { Tình trạng lo } \\
\text { âu }(\mathbf{n}, \mathbf{\%})\end{array}$ & $\begin{array}{c}\text { Trâmm cảm } \\
(\mathbf{n}, \mathbf{\%})\end{array}$ \\
\hline Bình thường: 0-7 & $14(35 \%)$ & $18(45 \%)$ \\
\hline Có dấu hiệu: 8-10 & $11(27,5 \%)$ & $12(30 \%)$ \\
\hline $\begin{array}{c}\text { Thực sự có bệnh: } \\
11 \text {-21 }\end{array}$ & $15(37,5 \%)$ & $10(25 \%)$ \\
\hline
\end{tabular}

Nhận xét: bảng 1 cho thấy trong 40 bệnh nhân có $27,5 \%$ trường hợp có dấu hiệu lo âu và $30 \%$ có dâu hiệu trầm cảm. Tỉ lệ thực sự lo âu là $37,5 \%$ và trầm cảm là $25 \%$.

Bảng 2. Điểm HADS theo giới ở 40 bệnh nhân

\begin{tabular}{|c|c|c|c|}
\hline \multirow{2}{*}{ Giới } & Điểm HADS & $\begin{array}{c}\text { Tình } \\
\text { trạng lo } \\
\text { âu }(\mathbf{n}, \%)\end{array}$ & $\begin{array}{c}\text { Trâm } \\
\text { cảm } \\
(\mathbf{n}, \%)\end{array}$ \\
\hline \multirow{2}{*}{ Nữ } & Bình thường: 0 - 7 & $4(16 \%)$ & $7(28 \%)$ \\
\cline { 2 - 4 } & Có dấu hiệu: $8-10$ & $9(36 \%)$ & $10(40 \%)$ \\
\hline
\end{tabular}

\begin{tabular}{|c|c|c|c|}
\hline & $\begin{array}{l}\text { Thực sự có } \\
\text { bệnh: } 11 \text {-21 }\end{array}$ & $12(48 \%)$ & $8(32 \%)$ \\
\hline & Tống & $25(100 \%)$ & $25(100 \%)$ \\
\hline & Bình thường: 0 - 7 & $\begin{array}{c}10 \\
(66,7 \%)\end{array}$ & $11(73,4 \%)$ \\
\hline Nam & Có dấu hiệu: 8 - 10 & $2(13,3 \%)$ & $2(13,3 \%)$ \\
\hline & $\begin{array}{l}\text { Thực sự có } \\
\text { bệnh: } 11-21\end{array}$ & $3(20 \%)$ & $2(13,3 \%)$ \\
\hline & Tống & $15(100 \%)$ & $15(100 \%)$ \\
\hline
\end{tabular}

Nhận xét: Bảng 2 cho thấy trong 25 bệnh nhân nữ thì tỉ lệ có dấu hiện lo âu là $36 \%$ và thực sự lo âu là $48 \%$; có $40 \%$ có dấu hiệu trầm cảm và thực sự trâm cảm ở $32 \%$ bệnh nhân. Đối với bệnh nhân nam thì chỉ có $13,3 \%$ có dấu hiệu lo âu và $20 \%$ lo âu thực sự; tî lệ có dấu hiệu trầm cảm và thực sự trầm cảm ở nam giới như nhau với $13,3 \%$.

\section{BÀN LUÂ̂N}

Nghiên cứu của chúng tôi cho thấy tỉ lệ lo âu và trầm cảm đanh giá theo thang điểm HADS ở bệnh nhân đau thắt lưng mạn tính do thoái hóa cột sống thắt lưng chiếm tỉ lệ khá cao với tỉ lệ bệnh nhân có lo âu là $65 \%$ và trầm cảm là $55 \%$. Trong đó có $27,5 \%$ số bệnh nhân bắt đầu có dấu hiệu lo âu và $30 \%$ có dấu hiệu trầm cảm, tỉ lệ lo âu thực sự là $37,5 \%$ và trâm cảm là $25 \%$. Polatin và cộng sự [4] đã nghiên cứu các trường hợp đau lưu mạn tính có liên quan đến các rối loạn tâm lý ở bệnh nhân theo thứ tự là trâm cảm, lạm dụng chất kích thích rồi đến rối loạn lo âu. Triệu chứng rối loạn lo âu xảy ra với tần suất tương đối cao ở những bệnh nhân bị đau thắt lưng mãn tính. Tương tự, các nghiên cứu đã chỉ ra rằng trầm cảm phổ biến ở người bệnh có biểu hiện đau lưng mạn tính [2]. Trầm cảm thường gặp ở những người bị đau thắt lưng và nó làm tăng cường độ đau, làm nặng khiếm khuyết về thể chất và tâm lý xã hội, lạm dụng sử dụng thuốc và khả năng thất nghiệp cao hơn [5]. Một nghiên cứu trên 70 bệnh nhân người Đức bị lưng đau mạn tính được báo cáo thì có $36 \%$ bênh nhân biểu hiện lo lắng (HAD-A> 10) và $29 \%$ có dấu hiệu trầm cảm (HAD-D> 8). Lo lắng bất thường và / hoặc trầm cảm là ghi nhận ở $47 \%$ bệnh nhân [6]. Trong nghiên cứu của chúng tôi $20 \%$ và $13 \%$ nam giới và $48 \%$ và $32 \%$ phụ nữ thực sự lo lắng và trầm cảm. Cả trầm cảm và tình trạng đau xảy ra thường xuyên hơn ở phụ nữ hơn nam giới. Tỉ lệ phụ nữ bị trầm cảm cao gần gấp đôi so với nam giới. Một nghiên cứu trên 140 người Pakistan bị đau thắt lưng mãn tinh cho thấy tỉ lệ bệnh nhân nam có rối loạn lo âu và tràm cảm là $14,28 \%$ và $16,42 \%$ nam, trong khi 
rối loạn lo âu và trầm cảm đã được tìm thấy ở $40,71 \%$ và $32,14 \%$ bệnh nhân nữ [7]. Dường như có sự khác biệt giữa nam và nữ về tỉ lệ lo lắng và trầm cảm ở các bệnh nhân đau thắt lưng mạn tính do thoái hóa. Sự khác biệt này có thể là do sự khác biệt về ngướng chịu đựng đau và khả năng chịu đựng của tình trạng tâmm lý ở nữ giới thấp hơn so với nam giới. Bằng chứng sinh học cho thấy rằng phụ nữ và đàn ông có thể có mức chịu dựng đau lưng mạn tính khác nhau. Mô hình sinh học dự đoán rằng phụ nữ dễ bị đau hơn và sẽ trải qua nhiều rối loạn chức năng tâm lý hơn do khả năng chịu đựng đau và sự thích ứng kém hơn so với nam giới. Bằng chứng xã hội tâm lý cho thấy rằng phụ nữ thường khó khăn khi đối phó với tình trạng đau thắt lưng mạn tính [8].

\section{KẾT LUẬN}

Nghiên cứu đã chỉ ra một cách rõ ràng rằng trong điều trị cho những bệnh nhân bị đau thắt lưng mạn tính do thoái hóa cột sống, các yếu tố tâm lý của bệnh nhân cũng có vai trò quan trọng, bởi lẽ những bệnh nhân bị thắt lưng mạn tính do thoái hóa cột sống có nguy cơ gặp phải rối loạn lo âu và trầm cảm. Ở những bệnh nhân này, tình trạng bệnh trở nên phức tạp do có thêm các dấu hiệu rối loạn về tâm lý như lo lắng và trầm cảm vì vậy cần được điều trị bởi liệu pháp thích hợp. Ngoài ra, một điều quan trọng trong điều trị bệnh nhân đau lưng mạn tinh đó là giới tình, cần hiểu rằng có sự khác biệt về tâm lý giữa nam và nữ và cách họ phản ứng với tình trạng đau lưng.

\section{TÀI LIÊU THAM KHẢO}

1. Croft P, Macfarlane G, Papageorgiou A, and et al, "Outcome of Low back pain general practice: a prospective study," BMJ, vol. 316, no. 2, pp. 1356-1359, 1998.

2. Rush. AJ, Polatin. $\mathbf{P}$, and Garchel. RJ., "Depression and chronic low back pain. Establishing priorities in treatment," Spine (Phila Pa 1976), vol. 25, pp. 2566-2571, 2000.

3. Snaith RP and Zigmond AS, "The hospital anxiety and depression scale," Br. Med. J. (Clin. Res. Ed)., vol. 292, no. 6516, p. 344, Feb. 1986, doi: 10.1136/bmj.292.6516.344.

4. Polatin. PB, Kinney. RK, and Gatchel. RJ, "Psychiatric illness and chronic low back pain," Spine (Phila Pa 1976), vol. 18, pp. 66-71, 1993.

5. Sathya P, "Prevalence of depression; Anxiety and stress in patients with Mechanical Low Back Pain .," Int J Ther. Rehab Res., vol. 4, no. 4, pp. 67-72., 2015.

6. Herrman $\mathbf{C}_{\text {., }}$ "International experiences with the Hospital Anxiety and Depression Scale. A review of validation data and clinical results.," J. Psychosom Res, vol. 42, pp. 17-41, 1997.

7. Sagheer M.A, "Association between Chronic Low Back Pain, anxiety and depression in patients at a tertiary care centre.," J Pak Med Assoc ., vol. 63, no. 6, pp. 213-218, 2013.

8. Sheffer, "Sex differences in presentation of Chronic Low Back Pain.," in Psychology of Women Quarterly, Printed in ÚSA: Blackwell Publishing., 2002, pp. 329-340.

\title{
ĐẶC ĐIỂM LÂM SÀNG TRÊN BỆNH NHÂN TRỨNG CÁ THÔNG THƯỜNG ĐẾN KHÁM VÀ ĐÎ̀̃U TRI TẠI BỆNH VIỆN ĐẠI HỌC Y DƯợC CẦN THO' NĂM 2018-2019
}

\author{
Trịnh Tiến Thành*, Huỳnh Văn Bá*, Trần Đăng Quyết**
}

\section{TÓM TẮT}

Mục tiêu: Mô tả một số đặc điểm lâm sàng trong bệnh trứng cá thông thường. Đối tượng và phương pháp: Mô̂ tả cắt ngang 241 trường hợp bệnh nhân được chẩn đoán trứng cá thông thường tại Phòng khám Da liễu - Bệnh viện Đại học Y Dược Cần Thơ trong thời gian từ 10/2018 đến 8/2019. Kết quả: Bênh nhân là học sinh-sinh viên chiếm tỉ lệ ca onhất $(50,6 \%)$. Vị trí tổn thương ở mặt chiếm tỉ lệ cao nhất

*Bệnh viện Đại họ Y Dược Cần Thơ

**Bênh viện Quân y 103

Chịu trách nhiệm chính: Huỳnh Văn Bá

Email: bs.ba_fob@yahoo.com.vn

Ngày nhận bài: 3/5/2021

Ngày phản biện khoa học: 22/5/2021

Ngày duyệt bài: 2/7/2021
$(99,2 \%)$, các vùng da khác tỉ lệ thấp hơn như lưng $(45,2 \%)$, ngực $(17,7 \%)$. Tổn thương nhân trứng cá hay gặp nhất $(96,3 \%)$, tiếp đến là sẩn viêm $(93,4 \%)$, mụn mủ $(89,6 \%)$, các tổn thương cục, giãn mạch, sẹo lồi, seo lõ̃m chiếm tỷ lê íthấp hơn. Tất cả các bênh nhân tham gia nghiên cứu đều có biểu hiện da nhờn ở các mức đô khác nhau. Kết luân: Đa số bênh nhân là học sinh-sinh viên. Vị trí hay gặp nhất là ở vùng mặt. Dang tổn thương hay gặp nhất là sẩn và nhân trứng cá. Tất cả các bệnh nhân tham gia nghiên cứu đều có biểu hiện da nhờn.

Tư khóa: Bệnh trứng cá, đặc điểm lâm sàng.

\section{SUMMARY \\ CLINICAL CHARACTERISTICS ON PATIENT \\ WITH ACNE VULGARIS TREATED ATCAN \\ THO UNIVERSITY OF MEDICINE AND PHARMACYIN 2018-2019}

